\title{
Toxicidades orais em pacientes adultos pós transplante de células-tronco hematopoiéticas: revisão integrativa da literatura
}

Oral toxicities in adult patients after hematopoietic stem cell transplantation: integrative literature review

Toxicidades orales en pacientes adultos después de un trasplante de células madre hematopoyéticas: revisión integral de la literatura

\author{
Pâmela Luísa Rocha Véras \\ ORCID: https://orcid.org/0000-0003-4175-6480 \\ Centro Universitário de Patos de Minas, Brasil \\ Email: pamelaveras@unipam.edu.br \\ Rodrigo Soares de Andrade \\ ORCID: https://orcid.org/0000-0001-6114-0929 \\ Centro Universitário de Patos de Minas, Brasil \\ E-mail: rodrigosa@unipam.edu.br \\ Gustavo Henrique Rocha Véras \\ ORCID: https://orcid.org/0000-0003-4267-6423 \\ Centro Universitário de Patos de Minas, Brasil \\ Email: gustavoveras@unipam.edu.br \\ Daniella Cristina Borges \\ ORCID: https://orcid.org/0000-0002-5424-5367 \\ Centro Universitário de Patos de Minas, Brasil \\ E-mail: daniellacbroges@ unipam.edu.br \\ Ivânia Aparecida Pimenta Santos Silva \\ ORCID: https://orcid.org/0000-0001-7012-8497 \\ Centro Universitário de Patos de Minas, Brasil \\ E-mail: ivaniapimenta@unipam.edu.br \\ Leonardo Bíscaro Pereira \\ ORCID: https://orcid.org/0000-0001-9790-9082 \\ Centro Universitário de Patos de Minas, Brasil \\ E-mail: leonardobiscaro@unipam.edu.br
}

\begin{abstract}
Resumo
O transplante de células-tronco hematopoiéticas (TCTH) é usado como tratamento padrão para uma variedade de doenças malignas hematológicas. Os pacientes passam por um tratamento mieloablativo intensivo antes de receber o transplante, ficando sob o risco de desenvolver complicações graves. A mucosite oral, xerostomia e infecções fúngicas, as mais comuns após o TCTH. Sendo assim, uma revisão integrativa da literatura foi conduzida com o objetivo de avaliar as possíveis toxicidades orais em pacientes pós TCTH, seus fatores de risco, sintomas e manifestações, buscando identificar a correlação entre o transplante de medula óssea com o desenvolvimento de alterações bucais. $\mathrm{O}$ estudo consta com uma revisão de caráter básico, do tipo bibliográfico, descritivo-explicativo, com análise integrativa e qualitativa. A busca foi feita com base em plataformas de pesquisa buscando os termos, "transplante de células-tronco hematopoiéticas", "toxicidades orais" e "mudanças orais". Foram incluídos artigos nas línguas inglesa e portuguesa, resultando em 15 artigos finais. Diversas são as toxicidades orais decorrentes da imunossupressão e tratamento antineoplásico com uso das células-tronco; as quais diminuem a sobrevida dos pacientes e sua qualidade de vida, além de estarem associadas a aumento de infecções sistêmicas, custos e dias de internação. Portanto, é de extrema importância que o cirurgião-dentista tenha domínio desse assunto, e saiba intervir de forma correta, não só para proporcionar conforto ao paciente, mas também evitar e/ou diminuir as complicações sistêmicas advindas da cavidade oral.
\end{abstract}

Palavras-chave: Transplante de células-tronco hematopoiéticas; Cavidade bucal; Transplante de medula óssea.

\begin{abstract}
Hematopoietic Stem Cell Transplantation (HSCT) is used as standard treatment for a variety of hematologic malignancies. Patients undergo intensive myeloablative treatment before receiving a transplant, putting them at risk of developing serious complications. Oral mucositis, xerostomia and fungal infections, the most common after HSCT. Thus, an integrative literature review was conducted with the aim of evaluating possible oral toxicities in post-HSCT patients, their risk factors, symptoms and manifestations, seeking to identify a correlation between bone marrow
\end{abstract}


transplantation and the development of oral changes. The study consists of a basic bibliographic review, descriptiveexplanatory, with integrative and qualitative analysis. A search was performed based on search platforms searching for the terms, "hematopoietic stem cell transplant", "oral toxicities" and "oral changes". Articles in English and Portuguese were included, publication in 15 final articles. There are several oral toxicities resulting from immunosuppression and antineoplastic treatment using stem cells; which decrease the survival of patients and their quality of life, in addition to being associated with an increase in systemic infections, costs and hospitalization days. Therefore, it is extremely important that dentists master this subject, and know how to intervene correctly, not only to provide comfort to the patient, but also to avoid and/or reduce systemic complications arising from the oral cavity.

Keywords: Hematopoietic stem cell transplantation; Buccal cavity; Bone marrow transplant.

\section{Resumen}

El trasplante de células madre hematopoyéticas $(\mathrm{TCMH})$ se utiliza como tratamiento estándar para una variedad de neoplasias malignas hematológicas. Los pacientes se someten a un tratamiento mielosupresor intensivo antes de recibir un trasplante, lo que los pone en riesgo de desarrollar complicaciones graves. Mucositis oral, xerostomía e infecciones fúngicas, las más frecuentes tras el TCMH. Así, se realizó una revisión integradora de la literatura con el objetivo de evaluar posibles toxicidades orales en pacientes post-TCMH, sus factores de riesgo, síntomas y manifestaciones, buscando identificar una correlación entre el trasplante de médula ósea y el desarrollo de cambios orales. El estudio consta de una revisión bibliográfica básica, descriptiva-explicativa, con análisis integrativo y cualitativo. Se realizó una búsqueda basada en plataformas de búsqueda que buscaban los términos "trasplante de células madre hematopoyéticas", "toxicidades orales" y "cambios orales". Se incluyeron artículos en inglés y portugués, publicación en 15 artículos finales. Existen varias toxicidades orales resultantes de la inmunosupresión y el tratamiento antineoplásico con células madre; que disminuyen la supervivencia de los pacientes y su calidad de vida, además de estar asociados a un aumento de infecciones sistémicas, costos y días de hospitalización. Por ello, es sumamente importante que los odontólogos dominen este tema, y sepan intervenir correctamente, no solo para brindar comodidad al paciente, sino también para evitar y / o reducir las complicaciones sistémicas derivadas de la cavidad bucal.

Palabras clave: Trasplante de células madre hematopoyéticas; Cavidad bucal; Transplante de médula osea.

\section{Introdução}

O transplante de células tronco hematopoiéticas (TCTH) é usado no tratamento de linfoma, leucemia e outras doenças hematológicas caracterizado como um processo agressivo e complexo que consiste na substituição de uma medula óssea doente ou deficiente, por células normais, e pode ser autólogo ou alogênico (Van Leeuwen, Potting, Huysmans \& Blijlevens 2019). Entretanto os pacientes que passarão por este tipo de tratamento são submetidos a quimioterapia e radioterapia de alta dosagem, o que pode gerar um quadro de imunossupressão intensa, período no qual há o desenvolvimento de lesões teciduais e infecções (Barrach, et al., 2014).

Uma complicação frequente nesses pacientes imunossuprimidos é a mucosite oral (MO), resultante das toxicidades dos medicamentos imunossupressores. Definida como um processo inflamatório ulcerativo da mucosa oral (Staudenmaier, et al., 2017), que resulta em uma fragilidade desta mucosa, sendo então considerado o efeito colateral mais debilitante da cavidade oral e também o mais frequente em pacientes pós TCTH, representando um fator de risco para possíveis infecções sistêmicas (Barrach, et al., 2014).

Outra complicação não tão frequente quanto à mucosite, mas não menos importantes são as infecções fúngicas oportunistas que se tornaram a principal causa de mortalidade infecciosa durante e após o TCTH (Markowski, et al., 2015). O agente etiológico de infecção fúngica mais frequente entre os pacientes submetidos ao TCTH é a Candida albicans (Markowski, et al., 2015).

Os fatores de risco para infecção fúngica sistêmica incluem gravidade e duração da neutropenia e a toxicidade da mucosa resultantes do regime de condicionamento durante o período inicial de transplante (primeiros 30 dias) (Markowski, et al., 2015). Também, adultos submetidos ao TCTH podem desenvolver a doença do enxerto contra o hospedeiro crônico (DECH), uma complicação séria, que afeta 50\% a $80 \%$ dos pacientes, sendo a boca um dos locais afetados (Gomes, et al., 2014). Alguns sintomas incluem xerostomia, mucoceles, atrofia da mucosa, pseudomembranas e úlceras (Gomes, et al., 2014).

Além dessas toxicidades orais já citadas, há relatos de outras complicações não tão comuns como, mucormicose, uma 
complicação infecciosa rara causada por fungos (Sakamoto, et al., 2018) e sinusite paranasal, condição infecciosa e inflamatória que envolve as vias aéreas nasais e paranasais (Mortellaro, et al., 2012).

\section{Metodologia}

Este é um estudo do tipo bibliográfico, descritivo-explicativo, com análise integrativa e qualitativa de caráter básico (Estrela, 2018).

\subsection{Estratégias de Busca}

Foram selecionados estudos indexados em bases de dados nacionais e internacionais (Pubmed e Scielo) até dezembro de 2020, utilizando os descritores "hematopoietic stem cell transplantation”, "buccal cavity”, "bone marrow transplant”, combinados com o operador booleano " $A N D$ ”.

\subsection{Critérios de inclusão e exclusão}

Os critérios de inclusão para encontrar os artigos que foram utilizados na pesquisa são:

(i) artigos que abordem as toxicidades orais decorrentes do TCTH; (ii) artigos nas línguas inglesa e portuguesa. Os critérios de exclusão foram definidos por: (i) artigos que abordaram as toxicidades em pacientes menores de 18 anos; (ii) artigos em que o foco estava no tratamento das toxicidades; (iii) artigos de outro idioma a não ser inglesa ou portuguesa; (iv) artigos duplicados nas bases de dados; (v) artigos com textos incompletos; (vi) artigos sem relação com o tema proposto.

Com base nos critérios citados e após remoção dos artigos que não encaixavam no intuito da pesquisa (Fluxograma Figura 1), foram encontrados 15 artigos que serão apresentados a seguir nos resultados.

\section{Resultados}

Do total de 750 artigos encontrados originalmente por meio da estratégia de busca na literatura através das palavraschave, foram incluídos na amostragem final 68 artigos. Os que foram excluídos nessa etapa inicial foram aqueles em que o título e resumo não se enquadravam no objetivo da pesquisa, também por motivos diversos (duplicação nas bases de dados, ausência de relação com o tema proposto, indisponibilidade dos textos completos ou por serem comentários ou resumos expandidos). Todos os outros estudos foram selecionados, lidos na íntegra e 15 artigos usados para a dissertação da pesquisa. 
Figura 1: Fluxograma do processo de busca na literatura.

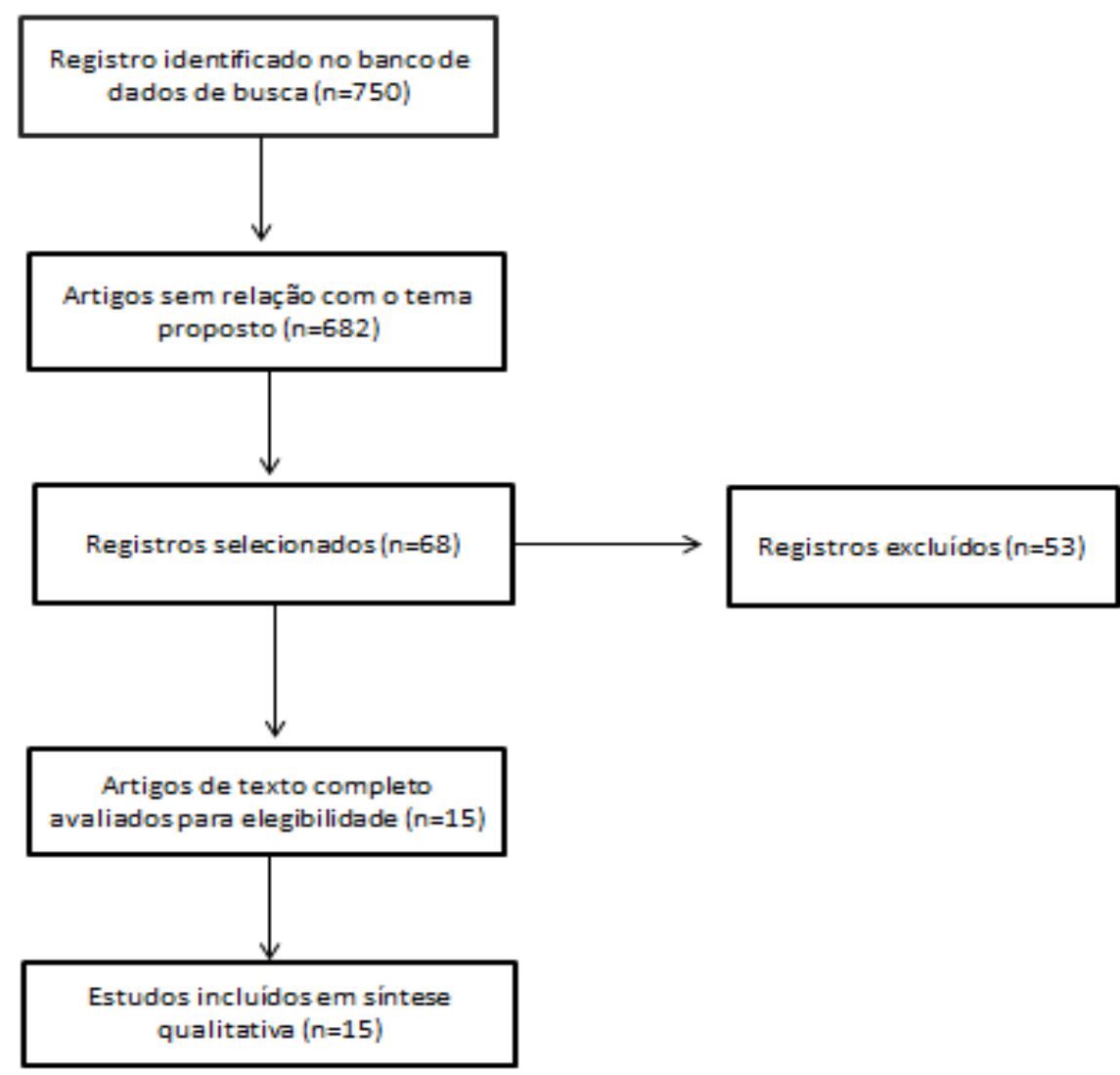

Fonte: Autores.

Tabela 1: Artigos utilizados na revisão integrativa sobre as Toxicidades orais em pacientes adultos pós transplante de célulastronco hematopoiéticas mostrando a metodologia, objetivo e resultado dos estudos de cada autor.

\begin{tabular}{|c|c|c|c|c|c|}
\hline Autor, Ano & Revista & $\begin{array}{l}\text { País de origem } \\
\text { do estudo }\end{array}$ & Objetivo & $\begin{array}{l}\text { Metodologi } \\
\text { a }\end{array}$ & Resultado \\
\hline $\begin{array}{l}\text { Epstein, Hancock } \\
\& \text { Nantel, } 2003 .\end{array}$ & $\begin{array}{l}\text { Oral Surgery, Oral } \\
\text { Medicine, Oral } \\
\text { Pathology, Oral } \\
\text { Radiology, and } \\
\text { Endodontology }\end{array}$ & Canadá. & $\begin{array}{l}\text { Examinar a relação } \\
\text { da colonização oral } \\
\text { por espécies de } \\
\text { Candida à infecção } \\
\text { sistêmica, } \\
\text { mortalidade e o } \\
\text { impacto do } \\
\text { tratamento } \\
\text { antifúngico. }\end{array}$ & $\begin{array}{l}\text { Análise } \\
\text { baseada em } \\
\text { resultados. }\end{array}$ & $\begin{array}{l}\text { Grande parte dos pacientes } \\
\text { desenvolveram algum grau de } \\
\text { mucosite ulcerativa, sendo a } \\
\text { complicação mais frequente. } \\
\text { A candidíase é a infecção oral } \\
\text { mais frequente em pacientes } \\
\text { com TCTH, a candida } \\
\text { albicans é a mais patogênica } \\
\text { das espécies. }\end{array}$ \\
\hline Luiz, et al., 2008. & $\begin{array}{c}\text { Revista Brasileira de } \\
\text { Hematologia e } \\
\text { Hemoterapia }\end{array}$ & Brasil & $\begin{array}{l}\text { Discutir questões } \\
\text { referentes aos } \\
\text { quadros inflamatórios } \\
\text { e infecciosos orais de } \\
\text { importância para o } \\
\text { paciente com TCTH. }\end{array}$ & $\begin{array}{c}\text { Revisão de } \\
\text { litaratura }\end{array}$ & $\begin{array}{c}\text { Pacientes submetidos ao } \\
\text { TCTH podem desenvolver: } \\
\text { MO, alterações nas glândulas } \\
\text { salivares e xerostomia, } \\
\text { DECH, alteração da } \\
\text { microbiota oral e cárie } \\
\text { dentária, infecções fúngicas e } \\
\text { virais. }\end{array}$ \\
\hline $\begin{array}{l}\text { Casco, et al., } \\
2011 .\end{array}$ & $\begin{array}{c}\text { Bone Marrow } \\
\text { Transplant }\end{array}$ & Austrália & $\begin{array}{c}\text { Avaliar a incidência } \\
\text { de complicações } \\
\text { orais de longo prazo } \\
\text { em sobreviventes de } \\
\text { TCTH. }\end{array}$ & $\begin{array}{c}\text { Estudo } \\
\text { transversal } \\
\text { multicêntri } \\
\text { co }\end{array}$ & $\begin{array}{c}\text { Maioria dos pacientes foram } \\
\text { diagnosticados com DECHc, } \\
\text { sendo o fator de risco mais } \\
\text { marcante a DECHc } \\
\text { preexistente. }\end{array}$ \\
\hline $\begin{array}{l}\text { Mortellaro, et al., } \\
2012 .\end{array}$ & $\begin{array}{c}\text { Journal of } \\
\text { Craniofacial Surgery } \\
\text { research }\end{array}$ & Itália & $\begin{array}{l}\text { Caso de uma } \\
\text { adolescente com } \\
\text { diagnóstico de } \\
\text { recidiva combinada } \\
\text { de leucemia } 2 \text { anos }\end{array}$ & $\begin{array}{l}\text { Relato de } \\
\quad \text { caso }\end{array}$ & $\begin{array}{l}\text { A sinusite é uma possível } \\
\text { complicação infecciosa após } \\
\text { o TCTH. A incidência de } \\
\text { rinossinusite em pacientes } \\
\text { submetidos ao TCTH varia de }\end{array}$ \\
\hline
\end{tabular}




\begin{tabular}{|c|c|c|c|c|c|}
\hline & & & $\begin{array}{l}\text { após o término da } \\
\text { quimioterapia que, } \\
120 \text { dias após o } \\
\text { transplante, apresenta } \\
\text { lesões erosivas da } \\
\text { mucosa palatina no } \\
\text { hemipalato esquerdo. }\end{array}$ & & $\begin{array}{l}1 \% \text { a } 33 \% \text { e é mais comum } \\
\text { nos transplantes alogênicos } \\
\text { do que nos autólogos. }\end{array}$ \\
\hline Sonis, 2013. & $\begin{array}{l}\text { Livro educacional da } \\
\text { American Society of } \\
\text { Clinical Oncology }\end{array}$ & Estados Unidos & $\begin{array}{l}\text { Fornecer uma visão } \\
\text { geral da pesquisa de } \\
\text { ponta sobre a } \\
\text { microflora oral e a } \\
\text { mucosite. }\end{array}$ & $\begin{array}{l}\text { Revisão de } \\
\text { literatura }\end{array}$ & $\begin{array}{l}\text { As bactérias associadas à } \\
\text { periodontite parecem ser } \\
\text { capazes de retardar a } \\
\text { cicatrização de feridas e } \\
\text { influenciar a mucosite. }\end{array}$ \\
\hline $\begin{array}{l}\text { Barrach, et al., } \\
2013 .\end{array}$ & $\begin{array}{l}\text { Brazilian Journal of } \\
\text { Otorhinolaryngology }\end{array}$ & Brasil & $\begin{array}{l}\text { Relatar um protocolo } \\
\text { de gerenciamento de } \\
\text { doenças bucais antes } \\
\text { e após TCTH. }\end{array}$ & $\begin{array}{l}\text { Estudo } \\
\text { clínico } \\
\text { prospectivo }\end{array}$ & $\begin{array}{l}\text { As alterações orais mais } \\
\text { frequentes foram: gengivite, } \\
\text { pericoronarite do terceiro } \\
\text { molar, úlceras e mucosite } \\
\text { associada a toxicidade dos } \\
\text { fármacos. }\end{array}$ \\
\hline $\begin{array}{c}\text { Gomes, et al., } \\
2014 .\end{array}$ & $\begin{array}{c}\text { Revista brasileira de } \\
\text { hematologia e } \\
\text { hemoterapia }\end{array}$ & Brasil & $\begin{array}{c}\text { Avaliar as } \\
\text { características orais } \\
\text { da DECH após o } \\
\text { TCTH. }\end{array}$ & $\begin{array}{c}\text { Estudo } \\
\text { trasnversal } \\
\text { multicêntri } \\
\text { co }\end{array}$ & $\begin{array}{c}\text { A DECH afeta mais da } \\
\text { metade dos pacientes adultos } \\
\text { após o TCTH. Placas } \\
\text { liquenóides/ hiperceratóticas, } \\
\text { lesões eritematosas, } \\
\text { xerostomia e hipossalivação } \\
\text { foram as características orais } \\
\text { mais comumente relatadas. }\end{array}$ \\
\hline $\begin{array}{l}\text { Markowski, et } \\
\text { al., } 2015\end{array}$ & $\begin{array}{c}\text { Medical science } \\
\text { monitor: } \\
\text { international medical } \\
\text { journal of } \\
\text { experimental and } \\
\text { clinical research }\end{array}$ & Polônia & $\begin{array}{l}\text { Analisar o espectro } \\
\text { da microflora fúngica } \\
\text { do trato respiratório } \\
\text { em pacientes } \\
\text { submetidos ao } \\
\text { TCTH. }\end{array}$ & $\begin{array}{l}\text { Estudo de } \\
573 \\
\text { pacientes } \\
\text { transplanta } \\
\text { dos ou } \\
\text { análise } \\
\text { retrospecti } \\
\text { va. }\end{array}$ & $\begin{array}{c}\text { Complicações pós TCTH: } \\
\text { lesões de barreira mucosa, } \\
\text { neutropenia prolongada, } \\
\text { doença do enxerto contra } \\
\text { hospedeiro crônica e } \\
\text { infecções oportunistas. } \\
\text { A taxa geral de colonização } \\
\text { fúngica após TCTH é } \\
\text { significativa. }\end{array}$ \\
\hline $\begin{array}{l}\text { Anand, et al., } \\
2016 .\end{array}$ & $\begin{array}{c}\text { Supportive Care in } \\
\text { Cancer }\end{array}$ & Estados Unidos & $\begin{array}{l}\text { Avaliar o impacto da } \\
\text { depleção de células T } \\
\text { pela seleção de CD34 } \\
\text { + na incidência e } \\
\text { gravidade da } \\
\text { mucosite orofaríngea } \\
\text { (OM) }\end{array}$ & $\begin{array}{l}\text { Estudo } \\
\text { retrospecti } \\
\text { vo }\end{array}$ & $\begin{array}{c}\text { Mucosite oral é a pior } \\
\text { complicação isolada do } \\
\text { condicionamento } \\
\text { mieloablativo. Grau } 2 \text { a } 4 \\
\text { foram os mais observados. }\end{array}$ \\
\hline Toro, et al., 2016. & $\begin{array}{c}\text { Suporte Care Câncer } \\
\text { Biology of Blood and } \\
\text { Marrow } \\
\text { Transplantation }\end{array}$ & Estados Unidos & $\begin{array}{c}\text { Comparar a } \\
\text { incidência de } \\
\text { toxicidades e } \\
\text { complicações em } \\
\text { pacientes edêntulos e } \\
\text { dentados submetidos } \\
\text { a TCTH autólogo } \\
\text { para mieloma } \\
\text { múltiplo. }\end{array}$ & $\begin{array}{l}\text { Estudo } \\
\text { caso- } \\
\text { controle } \\
\text { retrospecti } \\
\text { vo }\end{array}$ & $\begin{array}{c}\text { Não houve diferenças } \\
\text { significativas na incidência } \\
\text { de bacteremia, febre, } \\
\text { gravidade da mucosite oral ou } \\
\text { outras complicações entre } \\
\text { pacientes edêntulos e } \\
\text { dentados durante o TCTH } \\
\text { autólogo. }\end{array}$ \\
\hline $\begin{array}{c}\text { Staudenmaier, et } \\
\text { al., } 2017 .\end{array}$ & $\begin{array}{c}\text { Supportive Care in } \\
\text { Cancer }\end{array}$ & Alemanha & $\begin{array}{l}\text { Determinar o impacto } \\
\text { da mucosite oral } \\
\text { (MO) na qualidade de } \\
\text { vida relacionada à } \\
\text { saúde (QVRS) e nos } \\
\text { sintomas e funções } \\
\text { associados à } \\
\text { qualidade de vida em } \\
\text { pacientes submetidos } \\
\text { ao TCTH. }\end{array}$ & $\begin{array}{c}\text { Estudo } \\
\text { observacio } \\
\text { nal } \\
\text { prospectivo } \\
\text { e não } \\
\text { intervencio } \\
\text { nista }\end{array}$ & $\begin{array}{c}\text { Há um grande impacto da } \\
\text { mucosite oral na qualidade de } \\
\text { vida. } \\
\text { Prevalência no } \\
\text { desenvolvimento de mucosite } \\
\text { oral. Foram observados MO } \\
\text { de grau I, II, III e IV. } \\
\text { Os pacientes relataram sentir } \\
\text { dor intensa, moderada e leve } \\
\text { devido a MO. }\end{array}$ \\
\hline $\begin{array}{l}\text { Sakamoto, et al., } \\
2018 .\end{array}$ & $\begin{array}{l}\text { The Japanese Society } \\
\text { of Internal Medicine }\end{array}$ & Japão & $\begin{array}{c}\text { Relatar um caso raro } \\
\text { de mucormicose oral } \\
\text { após TCTH } \\
\text { alogênico }\end{array}$ & $\begin{array}{l}\text { Relato de } \\
\text { caso }\end{array}$ & $\begin{array}{c}\text { Complicação infecciosa rara: } \\
\text { mucormicose oral. } \\
\text { Fatores de risco que também } \\
\text { são complicações decorrentes } \\
\text { do TCTH: neutropenia } \\
\text { prolongada, doença do } \\
\text { enxerto contra hospedeiro } \\
\text { crônica, mucosite oral. }\end{array}$ \\
\hline $\begin{array}{c}\text { Van Leeuwen, et } \\
\text { al., } 2019 .\end{array}$ & $\begin{array}{c}\text { Biology of Blood and } \\
\text { Marrow } \\
\text { Transplantation }\end{array}$ & Holanda & $\begin{array}{c}\text { Avaliar as mudanças } \\
\text { na função e } \\
\text { composição salivar } \\
\text { antes e após o TCTH. }\end{array}$ & $\begin{array}{l}\text { Revisão } \\
\text { sistemática }\end{array}$ & $\begin{array}{l}\text { Complicações orais comuns: } \\
\text { MO e DECH que pode afetar } \\
\text { as glândulas salivares, } \\
\text { resultando em hipossalivação } \\
\text { e xerostomia. }\end{array}$ \\
\hline
\end{tabular}




\begin{tabular}{|c|c|c|c|c|c|}
\hline $\begin{array}{l}\text { Berger, et al., } \\
2020 .\end{array}$ & $\begin{array}{c}\text { Supportive Care in } \\
\text { Cancer }\end{array}$ & Alemanha & $\begin{array}{l}\text { Determinar a } \\
\text { incidência, padrões } \\
\text { de tratamento, } \\
\text { pacientes, adesão e } \\
\text { custos da MO. }\end{array}$ & $\begin{array}{c}\text { Estudo } \\
\text { observacio } \\
\text { nal } \\
\text { prospectivo }\end{array}$ & $\begin{array}{c}\text {. MO tem um impacto } \\
\text { negativo na qualidade de } \\
\text { vida, associada a } \\
\text { sangramentos, infecções e } \\
\text { perda de peso. }\end{array}$ \\
\hline $\begin{array}{l}\text { Ferreira, et al., } \\
2020 .\end{array}$ & $\begin{array}{c}\text { Supportive Care in } \\
\text { Cancer }\end{array}$ & Brasil & $\begin{array}{c}\text { Caracterizar as } \\
\text { alterações gustativas } \\
\text { e a atrofia das papilas } \\
\text { gustativas observadas } \\
\text { no período de } \\
\text { neutropenia do } \\
\text { TCTH }\end{array}$ & $\begin{array}{c}\text { Estudo } \\
\text { preliminar }\end{array}$ & $\begin{array}{c}\text { Houve um aumento } \\
\text { significativo da hipogeusia e } \\
\text { disgeusia. O gosto amargo foi } \\
\text { o mais alterado. Mucosite } \\
\text { oral prolongada e transplante } \\
\text { autólogo foram fatores } \\
\text { preditivos de despapilação de } \\
\text { língua. }\end{array}$ \\
\hline
\end{tabular}

TCTH: transplante de células-tronco hematopoiéticas MO: mucosite oral

DECH: doença do enxerto contra hospedeiro crônica

MO: mucosite orofaríngea

Fonte: Autores.

\section{Discussão}

O TCTH é uma técnica terapêutica que tem por objetivo curar pacientes oncológicos e controlar a doença. O transplante é precedido por altas doses de condicionamento com quimioterápicos, o que pode resultar em toxicidades sistêmicas e efeitos colaterais (Ferreira, et al., 2020). É classificado como autólogo quando as células-tronco são derivadas do próprio paciente e como alogênico quando as células-tronco se originam de outra pessoa (doador) (Barrach, et al., 2014).

A intensa imunossupressão ocasionada pelos agentes quimioterápicos faz com que os pacientes transplantados estejam mais sujeitos a desenvolver infecções graves que podem ocorrer em qualquer fase do transplante, podendo ser ocasionadas por agentes etiológicos diferentes, como bactérias, fungos, vírus ou parasitas (Barrach, et al., 2014).

Durante a neutropenia grave, os microrganismos da cavidade oral tendem a se multiplicar, levando ao desenvolvimento de infecção local podendo se disseminar para a corrente sanguínea causando bacteremia e infecção grave (Toro, et al., 2016).

Diante dos achados a literatura mostra que a mucosite oral é indiscutivelmente a complicação oral mais frequente em pacientes com TCTH e também principal fator de risco para possíveis infecções sistêmicas, que ocorrem em cerca de 20 a 50\% dos pacientes, em especial naqueles com neutropenia associada (Barrach, et al., 2014). De acordo com Berger et al. (2020), a MO está associada a um impacto negativo na qualidade de vida, já que pode provocar infecções, perda de peso e inclusive atrasos no padrão do tratamento oncológico do paciente.

É um processo biológico complexo que envolve cinco fases (iniciação, a resposta ao dano primário - mensagem e sinalização, amplificação, ulceração e cura) devido a vários fatores, como os efeitos da quimioterapia sobre o epitélio, flora bacteriana da cavidade oral, ações mediadas por citocinas, e sua gravidade varia dependendo da idade do paciente, nível de neutrófilos, etc (Vagliano, et al., 2011).

A escala da OMS classifica a MO em cinco graus. Grau 0 corresponde a uma cavidade oral sem lesões, enquanto no grau 4, considerado a mucosite grave, há presença de marcadas alterações teciduais com eritema e ulceração envolvendo quase toda a mucosa, sangramento, dor acentuada e até mesmo incapacidade de comer (Vagliano, et al., 2011).

As formas mais graves de MO necessitam de atenção médica especial, como nutrição parenteral, profilaxia de infecção e fluido de substituição (Valeh, et al., 2017). Aproximadamente 40\% a 96\% dos pacientes com TCTH desenvolvem algum grau de mucosite. As razões para estas variações são os diferentes padrões de tratamento, regime de condicionamento ou pela ferramenta de avaliação da MO que for aplicada. Existem alguns fatores de risco para o desenvolvimento da MO, como tabagismo, idade, episódio anterior de MO, história de lesões orais, dentre outros (Berger, et al., 2020).

Anand et al. (2017), em seu estudo, constituído de 105 pacientes com neoplasias hematológicas observaram que 46,7\% dos pacientes desenvolveram MO graus 2-4, defendendo que a MO ocorre em até 75\% dos pacientes submetidos ao TCTH e que 
os fatores de risco incluem condicionamento mieloablativo, radioterapia e uso de metotrexato para profilaxia de DECH.

Staudenmaier et al. (2017), afirmam que entre $40 \%$ e $99 \%$ dos pacientes transplantados sofrem de MO, e que frequentemente, os pacientes precisam de nutrição líquida ou parenteral o que afeta diretamente na qualidade de vida. Em seu estudo envolvendo 45 pacientes, 58\% desenvolveram MO no período de acompanhamento de 3 semanas, sendo notável o impacto da $\mathrm{MO}$ em pacientes com TCTH.

De acordo com Laheij e Soet (2014) em seu estudo, quando a microflora oral está em desequilíbrio e as bactérias prejudiciais estão proliferando muito, as úlceras da MO podem se tornar mais dolorosas, extensas e com período de duração mais longo.

Outra complicação comum apresentada nos artigos foi o desenvolvimento da doença do enxerto contra hospedeiro crônica (DECHc), doença esta que pode causar sequelas transitórias e/ou permanentes, sendo que as manifestações orais podem ser consideradas um marcador da doença, já que normalmente são seus primeiros sinais e consideradas importantes causas de morbidade e perda de qualidade de vida (Gomes, et al., 2014).

Gomes, et al. (2014), em se estudo envolvendo 57 pacientes, relatou que 77,2\% desenvolveram DECHc e que 88,63\% desses pacientes apresentavam características orais. Os órgãos mais afetados foram boca, pele, fígado, olhos e pulmões, sendo a boca o local mais frequentemente afetado $(88,63 \%)$. As características mais encontradas foram lesões orais e xerostomia.

$\mathrm{Na}$ cavidade oral as lesões tem características clínicas semelhantes ao líquen plano, com presença de inflamação, perda do pontilhado da gengiva inserida, sendo estas as alterações precoces; nas formas mais graves há presença de lesões erosivas e dor, afetando de 50\% a 80\% dos pacientes adultos submetidos ao TCTH (Gomes, et al., 2014). Segundo Luiz, et al. (2008), as lesões estão localizadas geralmente em mucosa jugal, labial e na língua, podendo ser confundidas com lesões auto-imunes.

A DECHc oral pode estar associada a outras lesões, como mucocele, candidíase e desenvolvimento de pseudomembranas mucofibrosas, sendo que o grau de envolvimento oral pode ser extenso e uma fonte de dor significativa, que torna a alimentação prejudicada e impede a manutenção da saúde oral e dentária (Casco, Kerridge \& Schifter, 2012).

Casco, Kerridge e Schifter (2012) e Luiz, et al., (2008), respectivamente, defendem em seus estudos que a DECHc ocorre em $40 \%$ a $70 \%$ dos sobreviventes com TCTH e pode envolver a cavidade oral como o principal ou único local de envolvimento, em 50-83\% dos afetados, e $72 \%$ a $83 \%$. Os fatores de risco associados a DECHc incluem aumento da idade do paciente, uso de um doador não relacionado, história prévia de DECHc, dentre outros (Casco, Kerridge \& Schifter 2012).

Além dessas toxicidades orais já mencionadas, outra bastante comum é o desenvolvimento de infecções fúngicas que são uma das principais causas de morbidade e mortalidade por infecção após TCTH, sendo que a taxa de infecções fúngicas varia dependendo do acesso e uso de agentes antifúngicos ativos (Markowski, et al., 2015).

De acordo com Markowski, et al. (2015), Aspergillus e Candida são os agentes etiológicos mais comuns em pacientes com TCTH. Os fatores de risco durante o período inicial do TCTH são neutropenia e a toxicidade da mucosa, já a terapia imunossupressora para DECHc seria o principal fator de risco no estágio posterior. Em seu estudo envolvendo 573 pacientes submetidos a TCTH devido a neoplasias hematológicas, a taxa geral de colonização fúngica foi de 19\%, com incidência estatisticamente maior entre pacientes alogênicos, sendo Candida Albicans a espécie mais frequentemente encontrada e a faringe o local de colonização mais comum.

Epstein, Hancock e Nantel, (2003), também defende as espécies de Candida como sendo os organismos fúngicos mais comuns em receptores de TCTH, sendo a duração e gravidade da neutropenia fator de risco para infecção fúngica sistêmica. O condicionamento pré-transplante com irradiação de corpo inteiro e desenvolvimento de mucosite ulcerativa também foram associados a risco aumentado de colonização. Em seu estudo foram avaliados 115 pacientes com TCTH e a taxa de colonização por Candida foi de 31\%, sendo a orofaringe o local comum para o desenvolvimento da infecção.

Além dos fatores de risco já mencionados, Luiz, et al. (2008), afirmam que o uso de antibióticos de amplo espectro e 
de esteróides, DECH e xerostomia também contribuem para maior probabilidade de desenvolvimento de infecções fúngicas e que 15\% a 56\% dos pacientes com TCTH desenvolvem infecções fúngicas, além disso cerca de 1/3 desses vão a óbito.

Uma infecção rara, mas importante de ser mencionada é a mucormicose, cuja incidência gira em torno de $0,6 \%$ em pacientes com TCTH. É uma infecção fúngica, aguda e invasiva que se manifesta em seis formas clínicas, incluindo a oral (Sakamoto, et al., 2018). O diabetes mellitus mal controlado tem sido o fato de risco mais comum, porém o TCTH em pacientes imunocomprometidos aumenta as chances do desenvolvimento de infecções fúngicas invasivas (Metzen, et al., 2012).

\section{Conclusão}

Com base nesta revisão integrativa pode-se concluir que toxicidades orais decorrentes da terapia antineoplásica são bastante comuns, sendo as principais, mucosite oral, doença do enxerto contra hospedeiro crônica e infecções fúngicas. Fatores de risco relacionados ao paciente e/ou a terapia afetam diretamente no desenvolvimento dessas complicações.

Essas alterações são de séria preocupação, já que não tratadas, têm potencial risco de disseminação sistêmica, além de influenciarem na qualidade de vida dos pacientes, nos custos e dias de internação. Portanto, como profissionais da área da saúde, é de extrema importância o cirurgião-dentista ter domínio desse assunto e conhecimento básico das possíveis alterações orais decorrentes do TCTH, para intervir mais rapidamente no tratamento das lesões e contribuir para uma melhora na qualidade de vida do paciente.

São necessários mais estudos seguindo essa linha de pesquisa, já que as toxicidades orais decorrentes do TCTH são as primeiras manifestações de efeitos colaterais do tratamento anti-neoplásico hematológico e causam grande prejuízo na sobrevida dos pacientes transplantados e muitos profissionais negligenciam nesse quesito. Além disso, como já mencionado anteriormente, as lesões bucais geralmente são os primeiros sinais pós TCTH, se tratadas rapidamente é possível até mesmo conter infecções sistêmicas, e proporcionar enormes benefícios para o paciente.

\section{Referências}

Anand, A., Anandi, P., Jain, N. A., Lu, K., Dunavin, N., Hourigan, C. S., Le, R.Q., Chokshi, P. D., Ito, S., Stroncek, D. F., Sabatino, M., Barrett, A. J., \& Battiwalla, M. (2016). CD34+ selection and the severity of oropharyngeal mucositis in total body irradiation-based allogeneic stem cell transplantation. Support Care Cancer, 24(2), 815-822.

Barrach, R. H., Souza, M. P., Silva, D. P. C., Lopez, P. S. \& Montovani, J. C. (2014). Oral changes in individuals undergoing hematopoietic stem cell transplantation. Brazilian journal of otorhinolaryngology, 81(2), 141-147.

Berger, K., Staudenmaier, T., Cenzer, I., Crispin, A., Strobach, D., \& Ostermann, H. (2019). Epidemiology, patient adherence, and costs of oral mucositis in routine care in stem cell transplantation. Supportive care in cancer: official journal of the Multinational Association of Supportive Care in Cancer, (28), 31133123

Casco, K. M., Kerridge, E. \& Schifter, M. (2012). Long-term oral complications of allogeneic haematopoietic SCT. Bone marrow transplantation, (47), 266270 .

Epstein, J. B., Hancock, P. J., \& Nantel, S. (2003). Oral candidiasis in hematopoietic cell transplantation patients: an outcome-based analysis. Oral surgery, oral medicine, oral pathology, oral radiology, and endodontics, 2(96), 154-163.

Estrela, C. (2018). Metodologia Científica: Ciência, Ensino, Pesquisa. Editora Artes Médicas.

Ferreira, M. H., Bezinelli, L. M., Eduardo, F. P., Lopes, R. M., Pereira, A. Z., Hamerschlack, N., \& Corrêa, L. (2020). Association of oral toxicity and taste changes during hematopoieticstem cell transplantation: a preliminary study. Supportive Care in Cancer, (28),1277-1287.

Gomes, A. O. F, Torres, S. R., Maiolino, A., Santos, C. W. N., Silva Junior, A., Correa, M. E. P., Moreira, M. C. R, \& Gonçalves, L. S. (2014). Early and late oral features of chronic graft-versus-host disease. Revista brasileira de hematologia e hemoterapia, 1(36), 43-49.

Laheij, A. M. G. A., \& Soet, J. J. (2014). Can the oral microflora affect oral ulcerative mucositis? Supportive and Palliative Care, 2 (8), $180-187$.

Luiz, A. C., Eduardo, F. P., Bezinelli, L. M., \& Correa, L. (2008). Alterações bucais e cuidados orais no paciente transplantado de medula óssea. Revista Brasileira de Hematologia e Hemoterapia, 30(6), 480-487. 
Research, Society and Development, v. 10, n. 13, e169101321103, 2021

(CC BY 4.0) | ISSN 2525-3409 | DOI: http://dx.doi.org/10.33448/rsd-v10i13.21103

Markowski, J., Helbig, G., Widziszowska, A., Likus, W., Kyrcz-Krzemień, S., Jarosz, U., Dziubdziela, W., \& Markiewicz, M. (2015). Fungal colonization of the respiratory tract in allogeneic and autologous hematopoietic stem cell transplant recipients: a study of 573 transplanted patients. Medical science monitor: international medical journal of experimental and clinical research, (21), 1173-1180.

Metzen, D., Böhm, H., Zimmermann, M., Reuther, T., Kübler, A. C. \& Müller-Richter, U. D. A. (2012). Mucormycosis of the head and neck. Journal of craniomaxillo-facial surgery: official publication of the European Association for Cranio-Maxillo-Facial Surgery, (40), $321-327$.

Mortellaro, C., Barat, V., Nesi, F., Bello, L., Bologna, G., Farronato, D., Lucchina, A. G., \& Linari, A. (2012). Intercurrent Infectious Diseases in Post-Stem Cell Transplant Patients: Paranasal Sinusitis. Journal of Craniofacial Surgery, 1(23), 153-157.

Sakamoto, H., Itonaga, H., Sawayama, Y., Taguchi, J., Saijo, T., Kuwatsuka, S., Hashisako, M., Kinoshita, N., Oishi, M., Doi, H., Kosai, K., Nishimoto,K., Tanaka, K., Yanagihara, K., Mukae, H., Izumikawa, K., \& Miyazaki, Y. (2018). Primary oral mucormycosis due to rhizopus microsporus after allogeneic stem cell transplantation. The Japanese Society of Internal Medicine, (57), 2567-2571.

Sonis, S. T. (2013). Oral mucositis in head and neck cancer: risk, biology, and management. American Society of Clinical Oncology educational book. American Society of Clinical Oncology, (33), 236-240.

Staudenmaier, T., Cenzer, I., Crispin, A., Ostermann, H., \& Berger, K. (2017). Burden of oral mucositis in stem cell transplant patients-the patients perspective. Supportive care in cancer: official journal of the Multinational Association of Supportive Care in Cancer, (26), $1577-1584$.

Toro, J. J., Gushiken, F. C., Schneider, D., Lee, S., Haile, D. J. \& Freytes, C. O. (2016). Edentulism and transplant-associated complications in patients with multiple myeloma undergoing autologous hematopoietic stem cell transplantation. Suporte Care Câncer, 24(8), 3411-3415.

Vagliano, L., et al. (2011). Incidence and severity of oral mucositis in patients undergoing haematopoietic SCT--results of a multicentre study. Bone marrow transplantation, (46), 727-732.

Valeh, M., Kargar, M., Mansouri, A., Kamranzadeh, H., Gholami, K., Heidari, K. \& Hajibabaei, M. (2017). Factors Affecting the Incidence and Severity of Orality Mucositis After Hematopoietic Stem Cell Transplantation. International Journal of Hematology-Oncology and Stem Cell Research, 2(12), 142-152.

Van Leeuwen, S. J. M., Potting, C. M. J., Huysmans, MC. D. N. J. M. \& Blijlevens, N. M. A. (2019). Salivary Changes before and after Hematopoietic Stem Cell Transplantation: A Systematic Review. Biology of blood and marrow transplantation: journal of the American Society for Blood and Marrow Transplantation, (25), 1055-1061. 